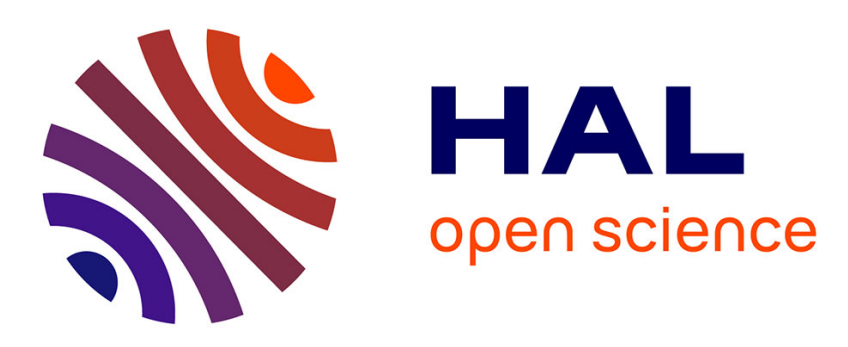

\title{
Coordination model for Supply Chain Management (SCM): an example in the application of the production planning process
}

Roberta Affonso, Bernard Grabot, Francois Marcotte

\section{- To cite this version:}

Roberta Affonso, Bernard Grabot, Francois Marcotte. Coordination model for Supply Chain Management $(\mathrm{SCM})$ : an example in the application of the production planning process. International Conference on Computers \& Industrial Engineering, 2009. CIE 2009, Jul 2009, Troyes, France. pp. 931-936. hal-00965905

\section{HAL Id: hal-00965905 https://hal.science/hal-00965905}

Submitted on 25 Mar 2014

HAL is a multi-disciplinary open access archive for the deposit and dissemination of scientific research documents, whether they are published or not. The documents may come from teaching and research institutions in France or abroad, or from public or private research centers.
L'archive ouverte pluridisciplinaire HAL, est destinée au dépôt et à la diffusion de documents scientifiques de niveau recherche, publiés ou non, émanant des établissements d'enseignement et de recherche français ou étrangers, des laboratoires publics ou privés. 


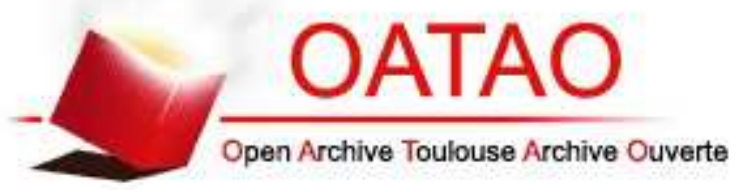

\section{Open Archive Toulouse Archive Ouverte (OATAO)}

OATAO is an open access repository that collects the work of Toulouse researchers and makes it freely available over the web where possible.

This is an author-deposited version published in: http://oatao.univ-toulouse.fr/ Eprints ID: 10937

\section{To cite this version:}

Affonso, Roberta and Grabot, Bernard and Marcotte, Francois Coordination model for Supply Chain Management (SCM): an example in the application of the production planning process. (2009) In: CIE09, 06 July 2009 - 09 July 2009 (Troyes, France).

Any correspondence concerning this service should be sent to the repository administrator: staff-oatao@,listes-diff.inp-toulouse.fr 


\title{
Coordination Model for Supply Chain Management (SCM): an Example in the Application of the Production Planning Process
}

\author{
Roberta Affonso ${ }^{1}$, Bernard Grabot ${ }^{2}$, François Marcotte ${ }^{2}$ \\ ${ }^{1}$ IRIT, Research Institute in Computer Science of Toulouse, 31000, France (roberta.affonso@univ-tlse2.fr) \\ ${ }^{2}$ University of Toulouse, LGP-ENIT, France (bernard@enit.fr)
}

\begin{abstract}
The coordination of companies in the supply chain (SC) is a pillar for achieving better overall performance. Although this problem is often studied, research does not usually take into account the influence of the relationships amongst companies on the supply chain performance. Marcotte et al. [1] propose a collaborative coordination model for the SCM. They suggest a taxonomy of collaborative situations which influence information processing all along the SC. They also propose reference models for coordination based on this taxonomy. In this paper, we illustrate information processing in the planning processes of a supply chain, according to different collaborative situations and to the corresponding reference models. The objective of this paper is to illustrate by way of examples the benefit of each company to process information according to a collaborative coordination model.
\end{abstract}

Keywords: supply chain, coordination, collaboration, modelling, illustration

\section{INTRODUCTION}

Since the introduction of Supply Chain (SC), a deep change has been noticed in the way companies coordinate one to the others.

In the past, companies were belonging to informal groups where each member worked focusing on its own interests, adopting a local approach. Nowadays, companies belong to a network of coordinated partners, where all information and all decisions are dedicated to achieve the global objective [2].

Nevertheless, even in such networks, and to consider one of the most important SC pillars, the partners are juridical and economically independent entities. This leads us to take into account the specific requirements of each SC company. The coordination and the collaboration within the SC will have the objective of satisfying the local requirements of each company but, at the same time, the global requirements imposed by the market.

If we also consider the fact that companies participate in several SC at the same time, coordination in the SC becomes a much more complex subject since companies receive sales forecasts and orders from different clients, and they have to handle requirement priorities according to both local constraints and local strategies.

After having studied real cases of coordination and collaboration in the SC, we have set the hypothesis that companies' features and SC features influence the companies' coordination in the SC. Moreover, the coordination mechanisms are in our opinion not the same in all SC nodes; this means that the kind of relationship between partners influences the coordination. We have also verified that the coordination problems are often detected and handled in an empirical way. There is clearly a lack of formalism to handle coordination problems.

In recent studies, coordination is often addressed without taking into account the different relationships that can exist in the SC. One of the studies that discuss this subject is [3]. In this study, the authors describe the relationship between Audi and Suzuki and their suppliers, according to their strategy of supplier choice. Nevertheless, the authors do not explain the way this relationship impacts coordination in the SC.

Marcotte et al. [1] have proposed a coordination model taking into account the relationship type between partners, aiming at identifying the coordination mechanism which is more appropriate to each type of relationship. The authors have suggested an application of the proposed coordination model as a diagnostic tool. Now, we want to show that this model can improve the production planning process in the SC.

This paper aims to demonstrate, through illustrations, the interest that each company has in processing information as suggested in the reference framework, in order to better coordinate production in the SC.

The paper is structured as follows: in the next section, we briefly present the coordination model for SC. In the third section ispresented the SC features, the assumptions and the scenarios considered in the examples. In the fourth section, we present the analysis and the results of each example. Finally, we discuss the conclusions and perspectives.

\section{COORDINATION MODEL FOR SC}

2.1 Basic model 
The coordination model for SCM proposed by Marcotte et al. [1] is based on GRAI model [4], and more specifically on the so called "decision frame" defined in the GRAI framework. A decision frame identifies the main elements required to make a decision [4]:

Objectives: results or performances to be reached by the added value process. Once the objectives are defined, they can be structured in a hierarchy.

Decision variables: parameters that modify the added value process properties in order to reach the expected objectives (performances).

Constraints: limits of use of a decision variable.

In the proposed coordination model, a decision frame represents for each company of the SC the necessary elements (local objectives, local decision variables and local constraints) to make a decision in the local coordination process. There is a decision frame for each coordination process level (long term, middle term, short term).

In a global point of view, a decision frame also represents the necessary elements (global objectives, global decision variables and global constraints) to make a decision in the global coordination process. This decision frame included sales forecasts, orders or requirement plans. The company can receive it from its direct customer, or from the SC pilot, if it exists.

A company in a SC has to take into account the SC requirements, in addition to its own local frame. Since a company usually participates to more than one $\mathrm{SC}$, it also has to take into account in its local coordination process the decision frame of all SCs in which it participates. A company must try to find a solution that respects all decision frames. When it is not possible, the arbitration between the local decision frame and requirements of all SCs has to be addressed. Depending on the type of relationship between companies in the $\mathrm{SC}$, the arbitration between the local decision frame and global decision frames will be different. Thus, the proposed coordination model defines different types of relationships in the SC (collaboration situations), and the coordination mechanisms for each situation.

\subsection{Taxonomy of collaboration situation}

After interviews in several companies, we have considered that two main criteria have a great influence on coordination: the power of the SC on the company and the power of the company on the SC. As a first step, if only two levels are considered for each characteristic (low and high), the proposed coordination model for the $\mathrm{SC}$ defines four collaboration situations summarized in Figure 1.

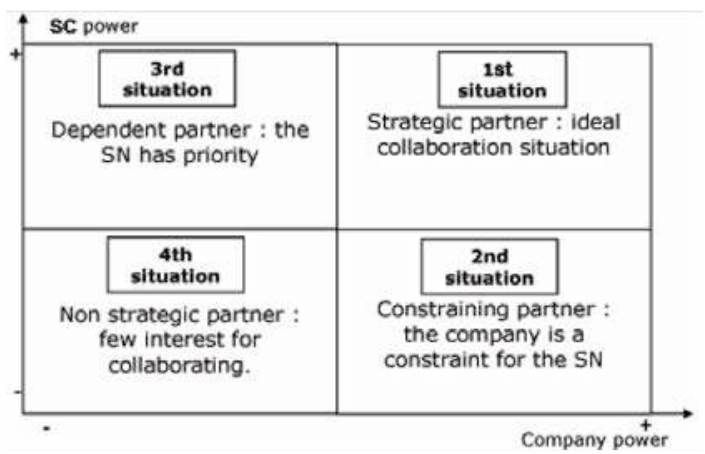

Figure 1: The collaboration situations [1]

1st situation: this is an ideal collaboration situation. The company is important for the SC and the SC is important for the company. In that case, the company is a strategic partner in the SC.

2nd situation: this is a constraining situation for the SC since the company is important for the SC but the SC cannot really influence the local decisions towards the $\mathrm{SC}$ requirements. The company is a constraining partner for the SC. The local decision frame will have priority in the local coordination process.

3rd situation: this is a situation of dependency of the company regarding the SC. The SC requirements will then have priority in the local coordination process. The company is a dependent partner.

4th situation: it is a situation of mutual indifference regarding coordination between the SC and the company. The company is a non-strategic partner regarding the $\mathrm{SC}$.

These four situations provide a first foundation to interpret the global decision frame in the local coordination process, and vice versa, as it is presented in the next section.

\subsection{Reference model for the coordination}

$>\quad$ Local mechanisms coordination

For each collaboration situation, the coordination model describes the way the global decision frame, which represents supply chain requirements, is taken into account in the local coordination process.

In the 1st situation, there is a real collaboration to arbitrate between local and global requirements. Then, the received procurement plan is processed as a decision frame. The result of this collaboration process will be a compromise based on local and global requirements.

In the 2nd situation, the company is a constraint for the $\mathrm{SC}$. It receives a procurement plan from the $\mathrm{SC}$, but in its local coordination process, the company will first take into account its local requirements. As a consequence, this procurement plan is not considered as an objective, but as a potential adjustment variable, allowing for example to smooth or adjust the workload 


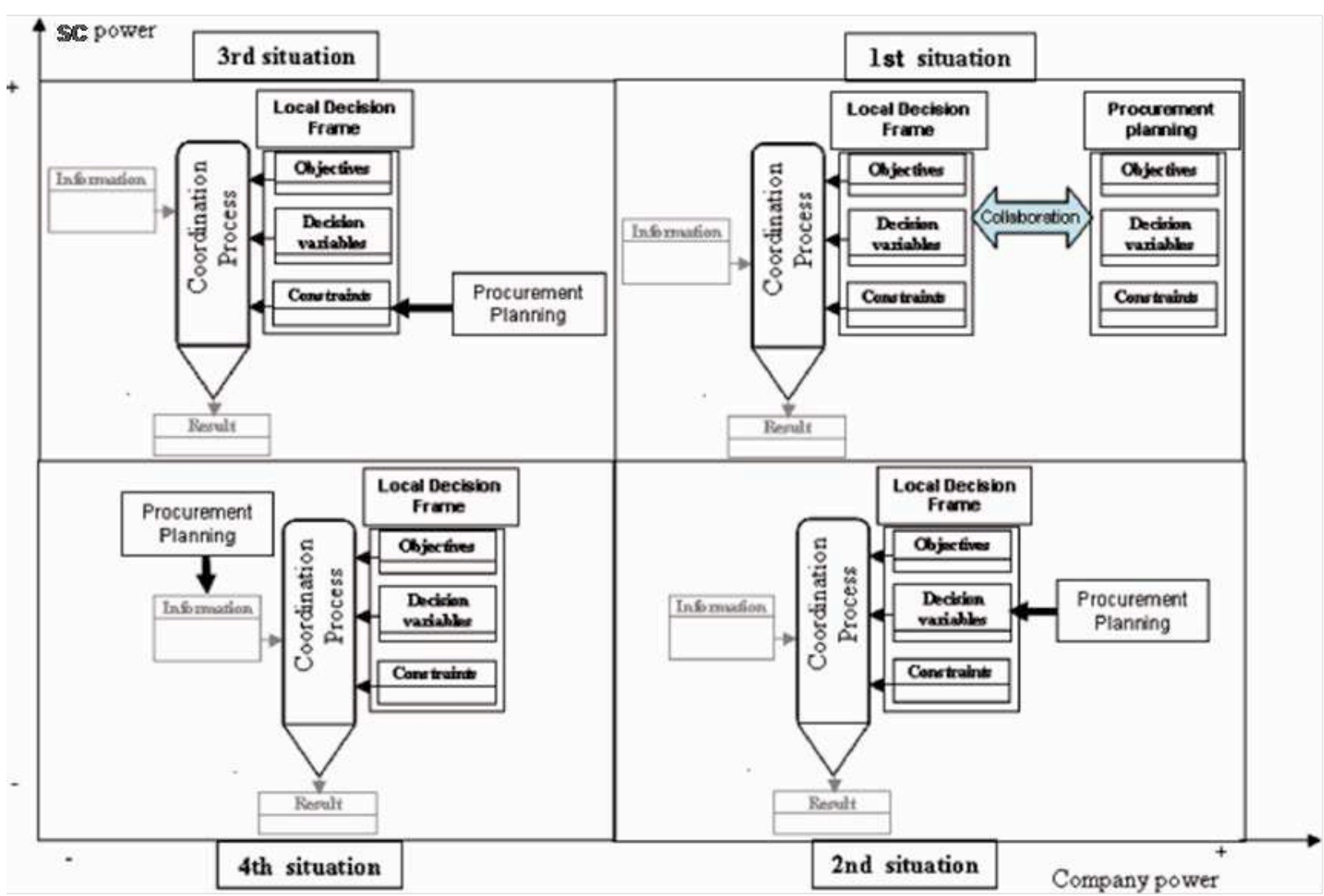

Figure 2: Local coordination mechanisms [1]

if necessary.

In the 3rd situation, the SC will impose its requirements. In that case, the company has no alternative but to respect the SC requirements. The procurement plan is so interpreted as a constraint which has to be respected.

Finally, in the 4th situation (mutual indifference), the procurement plan will only be considered as information among other requirements, to be integrated in the coordination process.

\section{$>$ Global mechanisms coordination}

After analysing the SC requirements, and according to the local collaboration situation, each SC partner will eventually negotiate or propose a solution to the SC partners. The proposed coordination model describes the way each partner should be considered in the coordination process at the level of the SC.

For a strategic partner (1st situation), there should be a negotiation. Company and SC build together a solution, in respect with the local decision frame and the SC requirements.

A constraining partner (2nd situation) promotes its own objectives. Then, the local coordination results are considered as a constraint to be respected by the SC.

For the dependent partner (3rd situation), one can consider that all the local decision variables are potentially available for the SC (limited by the local constraints related to these decision variables). Actually, the SC has the power to dictate its procurement plan on the company, which then uses its own decision variables in order to meet the SC requirements.

Finally, the non-strategic partner (4th situation) has a very low influence on the global coordination process. Its answer to the procurement plan is integrated as information to be taken into account.

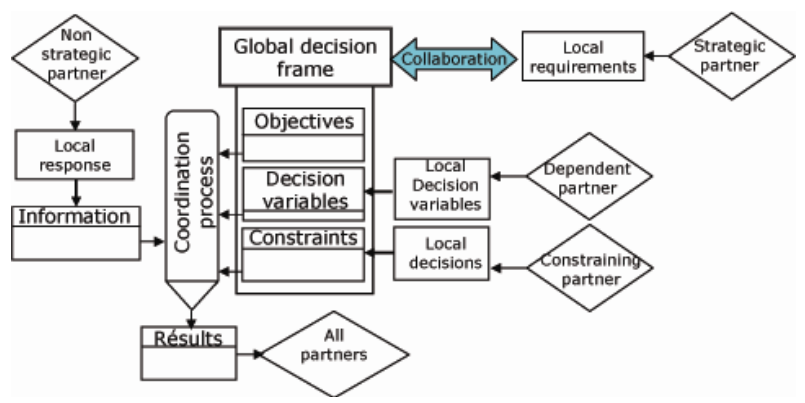

Figure 3: Global coordination mechanisms [1]

After briefly introducing the proposed coordination model for the SC, we now want to illustrate that different ways of processing information in the production planning stage may be relevant, depending on the proposed coordination mechanisms.

The aim is to illustrate, through examples, the interest of each company for processinginformation in consistence with it sreal use (objective, information, constraint...), which is not usually done.

In the next section are presented the example features and the application scenarios. 


\section{EXAMPLE FEATURES, ASSUMPTIONS AND SCENARIOS}

\subsection{Example features and assumptions}

$>\quad$ The supply chain and its partners

To illustrate the process of production planning according to the proposed coordination model, we have defined a simple but representative example of SC structure, composed by three companies: the supplier of raw materials, the subcontractor that manufactures subassemblies and the company that carries out the final assembly. Figure 4 illustrates the supply chain structure, and shows a simplified bill of materials. We assume that the subcontractor and the raw material supplier are also partners in other SCs.

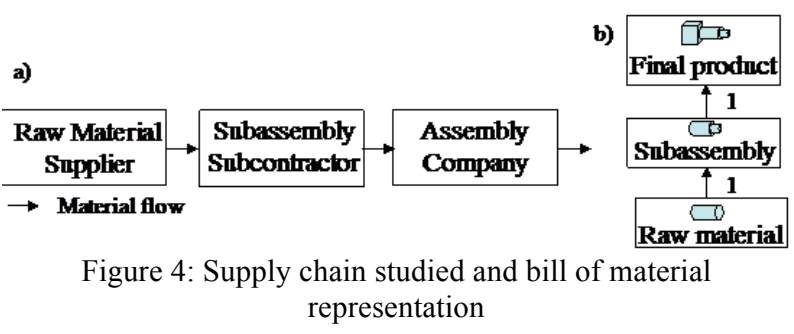

Technical data (lead time, average capacity, etc.) were also defined for the three companies of the SC.

We have considered that each company manages its direct upstream partner (point-to-point management). It allows to identify the roles and the responsibilities of each company well functioning SC.

\section{$>\quad$ Planning Rules}

As previously said, the companies in the SC are also partners in other SCs. Thus, we assume that in periods where the workload is more important than the capacity, the companies use different rules to arbitrate the priority between the received orders. In this situation, the requirements of the most important customer for the companies often have priority. In our example, the priority rules define the way a company shares its capacity between the requirements of different SCs in which it participates. These rules have been defined as identical for all the companies of the defined SC:

- requirements of the most important $\mathrm{SC}$, in terms of amount of business for the company, will have the priority. Then, the requirements of the second most important SC is considered, and so on.

- Companies must ensure a minimum service level related to the requirements of the least important SC. This minimum service level is a percentage of the average nominal order of the studied SC. For example, the company tries to deliver on time at least $50 \%$ of the average order of the SC. This rule intends to avoid the risk of a company not delivering at all one of the SC in which it participates.

Another rule used in production planning concerns the raw material supplier. In our illustrations, we assume that the cost of raw material inventory is "expensive", and that this raw material is scarce. We have assumed that this partner will never a priori use backlog Therefore, in the case when the workload is more important than the capacity, the decision of this partner will not be to anticipate production.

\subsection{Scenarios}

After defining the supply chain, which is the base of our illustration, and the rules for planning, we will now define the scenarios that we want to study.

In the first scenario, we will show that information is processed in the SC production plan according to the principles implemented in SCs. These principles were verified in our case studies conducted in the southwest part of France, where a significant number of companies work for the aerospace industry (see [1]).

In this scenario, we consider that the planning process is based on classic point-to-point coordination.

Companies are facing stresses related to raw material supplies for June. Sales forecasts relating to the most important SC (in terms of amount of business) of this supplier is significantly higher (over $20 \%$ ).

We analyze the way information is processed and how the system reacts to this stress.

In the second scenario, we consider the same stress in the supply chain. On the other hand, we analyze each SC partner, according to the coordination model, in order to identify the best way to take them into account in the planning process. We also analyze how the system reacts in this coordination model.

These illustrations are based on a typical S\&OP (Sales and Operations Planning) process, which is a crucial step in SC coordination [5]. The specific S\&OP used here is based on the one proposed by Affonso et al. [5], built with three levels: Sales, Production and Supply. All information process was performed in Excel ${ }^{\circledR}$.

In the next part, we present the illustrations.

\section{ILLUSTRATIONS}

\subsection{Information processing illustration - classic point-to-point coordination}

Through our case studies, which were limited to the aerospace industry, we have verified that companies of the studied SCs often try to coordinate themselves in a classic point-to-point model. Based on sales forecast, and considering the commitments defined with its partners about a production cycle corresponding to a given quantity, the SC pilot defines its production and establishes supply plans for its partners (subcontractors). To define these plans, it expresses its estimated requirements per period in a time horizon at least as long as the overall SC cycle time.

Since commitments defined with its partners in terms of 
cycle time are taken into account to establish these plans, the pilot considers that its partners are able to respect these plans. This process is the same for every SC node, and each company considers the supply plan received as a sale forecast. In our illustration, we will consider it as an order, because we do not distinguish the fixed, flexible and free zones in the supply plan sent from the client.

According to the situations described in our case studies, the information about delivery problems from suppliers are belatedly communicated all along the SC. Actually, when supply plans are structured in fixed and flexible zones, each of the studied company has a tendency to wait for firm orders (requested amounts confirmation), to inform its customers about difficulties it is facing to respect its commitments. This response time is especially long if the problem does not come from the non satisfied customer.

\section{$>$ Analysis and results}

After the increase in orders, the raw material supplier does not have enough capacity to respect supply plans of all SCs in which it participates. Considering the rule of capacity distribution between its SCs, he noticed that the requirements of the studied SC can not be completely satisfied. Moreover, as a said before, this partner does not anticipate its production when its capacity is not sufficient (expensive cost of storage). So, this partner decides to deliver to a client partially in July and to handle the remaining amount the following month.

The sub-assemblies subcontractor is informed lately about the supply problems. When this partner takes late receipt of the raw material in August, it has not enough capacity to completely catch up the urgent commitments This is done the following month. This problem generates an even longer delay, and additional raw material inventory cost for the subcontracting sub-assembly. The same issues are presented to the Assembly Company. These examples are summarised in Table 1.

In this illustration, we verify two types of information flow in the production planning process. The first one is the downstream to upstream flow, related to orders transmission. The second one is the upstream to downstream flow, related to adjustment information (response to the SC requirements), which is much more difficult to implement. Actually, suppliers and subcontractors often inform their customers too late about expected problems. The subcontractors usually react in this way because they can not identify these problems or because they hope to find a solution before the delivery date. In any case, it is often too late to reorganise production throughout the supply chain. This situation is a good representation of the inertia of the coordination process in SCs such as we have seen in case studies.
Table 1: Result of classic point-to-point coordination

\begin{tabular}{|l|c|c|c|}
\hline \multirow{2}{*}{ Month } & \multirow{2}{*}{$\begin{array}{c}\text { Stock } \\
\end{array}$} & Shortage & \multicolumn{2}{|c|}{ Inventory (product unit) } \\
\cline { 3 - 4 } & - & Assembl. Comp. & Subcontractor \\
\hline Aug. & 60 & - & 3 \\
\hline Sept. & 60 & 24 & - \\
\hline Oct. & 27 & - & - \\
\hline
\end{tabular}

\subsection{Information processing illustration according to the coordination model for the SCM}

In order to identify the bet way to take the partners into account in the coordination process, the coordination model is now applied to this SC. More precisely, we are going to identify the collaborative situation of each SC partner:

Assembly Company: this company can be considered the SC pilot.

The sub-assemblies subcontractor: this partner performs a non critical activity in the SC, but the studied SC represents an important amount of its business. Then, according to the proposed reference frame, this partner is considered as a dependent partner in the studied SC. The raw material supplier: this partner performs a critical activity in the $\mathrm{SC}$, and the last one has no important influence on its business. Then, this partner is considered as a constraining partner in the studied SC, according to the proposed reference frame.

Identifying the collaborative situation of a tier 1 partner, the assembly company can suppose that the global decision frame of the studied SC has the priority in the local coordination process of the subcontractor. Thus, this partner should not bring constraints back to the assembly company.

Nevertheless, increasing the analysis scope, we can verify that the raw material supplier is a constraining partner for sub-assemblies subcontractors. Thus, the studied SC objectives certainly do not have priority in its local coordination process. So, the response of this partner must be taken into account as a constraint in the subcontractor coordination process. Thus, the information flow, from upstream to downstream, will be more efficient, so that this constraint is taken into account as soon as possible in the subcontractor coordination process. If the subcontractor can not relax this constraint, it will inform the assembler so that this last one takes this constraint into account as soon as possible in its coordination of local processes.

\section{$>\quad$ Analyse and results}

In this illustration, after receiving a response from the raw material supplier related to its requirements, the subcontractor realises that it can not completely deal with its supplier constraints. The subcontractor decides to ask its supplier to anticipate, as much as possible, the production of raw material, which will be stored on the subcontractor site. Despite this anticipation, a part of the requirement will have to be delivered behind schedule. The subcontractor reorganises its production to support 
the workload in excess in the period that the overdue supply will be delivered. This partner also informs the assembly company about the supply problems. Thus, the assembly company has enough time to reorganise its production and can absorb the excess workload. This way, the partners can reduce the impact of supply problems all along the SC, and minimizes the overall delay.

In this situation, like in the first one, we consider two types of information flow in the production planning process. The first one is the downstream to upstream flow, related to orders transmission. The second one is the upstream to downstream flow, related to adjustment information (response to the $\mathrm{SC}$ requirements). Although, in this situation, the second flow is much more efficient. This flow represents the transfer of part of the subcontractor constraint to the assembly company. Once again, taking into account the collaborative situation of the raw material supplier related to the subcontractor, the assembly company can better anticipate a critical situation for subcontractor. The assembly company seeks a response from the subcontractor as soon as possible. This accelerates the information research of the subcontractor with its own supplier. As the dependent partner (subcontractor of sub-assemblies) is not able to completely relax the constraint from the constraining partner (raw material supplier), the subcontractor becomes itself a constraining partner for the SC pilot (Assembly Company).

Through this example, we can see the importance to identify the collaborative situation of SC partner. It allows us to verify the need, and the importance of having an effective upstream to downstream information flow. This allows for better constraints integration in the production planning process. The results of this second scenario are summarised in Table 2.

Table 2: Coordination results according to the coordination

\begin{tabular}{|l|c|c|c|}
\hline \multirow{2}{*}{ Month } & \multirow{2}{*}{$\begin{array}{c}\text { Stock } \\
\text { Shortage }\end{array}$} & \multicolumn{2}{|c|}{ Inventory (product unit) } \\
\cline { 3 - 4 } & - & Assembly Comp. & Subcontractor \\
\hline June & - & - & 20 \\
\hline Sept. & 40 & - & - \\
\hline
\end{tabular}

\section{CONCLUSION}

In this paper, we have presented a simplified example of a supply chain to illustrate different information processing models in the coordination between partners. In the first scenario, we have illustrated classic point-to-point coordination, widely applied in industry. We have shown that this coordination model can react slowly when the SC is facing stress. This is mainly due to the fact that this coordination model based on the principle of commitment between suppliers and customers, supposing that partners will be able to respect these commitments. This example seems to characterise many situations verified in case studies.

In the second scenario, we have analyzed the collaborative situation of each partner. This analysis allows us to identify the information flow necessary to have more effective coordination.

This approach is based on the identification of the constraints provided by SC partners. Then, these constraints must be integrated into the company planning process. In particular, this approach highlights the situations where information flows from upstream to downstream become essential to better organise the planning of each SC company.

Finally, the examples illustrate that the implementation of the proposed coordination mechanisms do not necessarily result in optimal planning for the SC pilot, but allow for a better constraint integration resulting from the relationships in the SC. Thus, it allows a better management of the problems arising from these relations, especially in the constraint propagation.

We highlight that the coordination model for the SC does not propose an ideal way to manage $\mathrm{SC}$ in order to reach an overall optimised performance. Indeed, this model suggests a framework that enables companies to identify the coordination mechanisms most appropriate according to the analysis of their collaboration situation.

\section{REFERENCES}

[1] Marcotte, F., Grabot, B., Affonso, R., "Cooperation models for Supply Chain Management", International Journal of Logistics Systems and Management, Vol. 5, No. 1, pp. 123-153, 2009.

[2] Sahin, F., Powell, R.E., "Information sharing and coordination in make-to-order supply chains", Journal of Operations Management, Vol. 23, No. 6, pp. 579-598, 2005.

[3] Demeter, K., Gelei, A., Jenei, I., "The effect of strategy on supply chain configuration and management practices on the basis of two supply chains in the Hungarian automotive industry", International Journal of Production Economics, Vol. 104, No. 2, pp. 555-570, 2006.

[4] Doumeingts, G., Chen, D., Vallespir, B., Fénié, P., "GRAI integrated methodology (GIM) and its evolutions: a methodology to design and specify advanced manufacturing systems", IFIP Transactions B: Computers Applications in Technology, Vol. B-14, pp.101-117, 1994.

[5] Affonso, R., Marcotte, F., Grabot, B., "Sales and operations planning (S\&OP): the supply chain pillar", Production Planning \& Control, Vol. 19, No. 2, pp. 132-141, 2008. 